\title{
On the Optimality of Delegating Pricing Authority to the Sales Force
}

An important decision facing sales managers today is precisely how much pricing authority should be delegated to the sales force. Received theory suggests that the salesperson's superior information about customers' valuations will invariably make price delegation profitable for the firm. The empirical evidence, however, reveals that firms that grant full pricing authority generate lower profits than firms that limit pricing authority. Given this state of affairs, the author develops and analyzes a formal model that examines the optimality of delegating pricing authority to the sales force. The model preserves the notion of superior information assumed in the literature but considers as well a negative feature of much concern to practitioners, namely, the suboptimal substitution of selling effort by price discounting. The model reveals that providing the salesperson with full pricing authority is not always optimal. Specifically, in some environments, it is appropriate to limit pricing authority because this decision forces the salesperson to target high-valuation customers. In addition, the model predicts that the commission rate offered to the salesperson should be higher when pricing authority is limited. The author concludes by summarizing the context, calculus, and implications of the model with a view to assisting managers charged with the price-delegation decision.

A $\mathrm{n}$ important decision facing sales managers today is precisely how much pricing authority should be delegated to the sales force. Dolan and Simon (1996) report that firms vary widely in this regard. Some give full pricing authority to their salespeople, whereas others grant only limited authority. Not surprisingly, the question of delegating pricing authority to the sales force has been examined in the marketing literature before (Lal 1986; Weinberg 1975). The main conclusion emerging from these studies is that as long as the incentives are properly aligned (i.e., based on gross margins and not on sales), the salesperson's superior knowledge about customers' valuations of the firm's offering will invariably make price delegation profitable for the firm.

Given these theoretical arguments in favor of delegating pricing authority to the sales force, Stephenson, Cron, and Frazier (1979) set out to investigate empirically the profit implications of price delegation. Consistent with theory, they focus their research efforts on an industry in which commissions are based on gross margins. In their analysis, responding firms are categorized into three groups: those providing their salespeople with no authority to deviate from list price, those allowing a specific percentage deviation from list price, and those granting full discretion with respect to pricing. Surprisingly, they find that firms that give salespeople the least pricing authority generate the highest levels of gross margin. A similar pattern of findings holds for the level of net profit (gross margin less salesperson compensation) enjoyed by the firm. Thus, Stephenson, Cron, and Frazier's empirical findings do not support the

Kissan Joseph is Associate Professor of Marketing, School of Business, University of Kansas. The author thanks the four anonymous $J M$ reviewers for several valuable comments on previous versions of the article. Financial support from the General Research Fund of the University of Kansas is gratefully acknowledged. theoretical prescription that favors a high degree of price delegation.

Stephenson, Cron, and Frazier (1979) conclude by emphasizing the need for additional research that examines the optimality of delegating pricing authority to the sales force. They identify five factors that can mitigate, or even reverse, the optimality of delegating pricing authority to the sales force. These factors, listed in order, are (1) the kind of sales behaviors that evolve when sales personnel are given pricing latitude, (2) the amount of superior information salespeople have about customer willingness to pay, (3) the nature of competitive behavior occurring under price delegation, (4) buyers' bargaining ability and behavior under price delegation (i.e., negotiation issues), and (5) control value of gross-margin commission systems.

In this article, I develop and analyze a theoretical model that explicitly incorporates two of the five factors highlighted by Stephenson, Cron, and Frazier. On the one hand, providing pricing authority to individual salespeople enables them to use their superior information about customer willingness to pay and thereby conclude a greater number of transactions. On the other hand, providing salespeople with pricing authority leads to the possibility of suboptimal tradeoffs between price and effort. In this connection, it is interesting to note that sales managers often complain that price latitude causes sales personnel to take the path of least resistance, that is, use discounting rather than expend effort on selling (Stephenson, Cron, and Frazier 1979, p. 26). Given these opposing considerations, my primary objective in this research is to examine the net effect of these two forces in influencing the price-delegation decision.

The limited focus of the present research does not imply that the other factors identified by Stephenson, Cron, and Frazier are unimportant. Rather, this narrow focus is designed to offer a sharp understanding of how two opposing considerations influence the optimality of the price- 
delegation decision. Indeed, such an approach is consistent with what Moorthy (1993) observes about the nature and role of theoretical modeling. While commenting that theoretical modeling has rapidly become an important style of research in marketing, he writes that real-world situations are incredibly complex. Many forces come into play, and what we observe as managerial actions are the results of all these forces. As such, inferring cause and effect from observed actions can be a daunting task. Consequently, by analyzing a limited aspect of reality, theoretical modeling enables an understanding of the specific effect of a force or a subset of forces.

In addition to analyzing the impact of two key forces, the model also helps shed light on a managerially relevant question: Does the extent of pricing authority affect the level of incentives offered to the salesperson? Specifically, should a firm contemplating a reduction in pricing authority increase, decrease, or leave unchanged the commission rate offered to the salesperson?

The main analytical findings are as follows: There are regions in the parameter space in which full price delegation is the most favorable course of action and others in which limiting pricing authority is the best strategy. This is an important conclusion because it provides a basis for reconciling the conflicting empirical evidence presented in the literature. In addition, the commission rate should be higher at firms that limit pricing authority. This finding suggests that firms making the transition from full pricing to limited pricing authority also need to increase the emphasis placed on incentive pay. This finding is noteworthy because intuition would suggest that placing greater limits on pricing might be accompanied by relaxing the emphasis placed on another control element, namely, the commission rate.

The rest of the article is organized as follows: I first review the relevant literature. This overview is followed by a description of the essential features of my research setting. Next, I present the impact and resolution of the two opposing forces within the model. Finally, I present the main results in the form of two propositions and conclude by outlining how the model may be used to assist managers charged with the price-delegation decision.

\section{Literature Review}

Dolan and Simon (1996) succinctly delineate the arguments for and against delegating pricing authority to the sales force. An argument for price delegation is that, in general, the salesperson is in the best position to assess customer willingness to pay. Consequently, delegating pricing authority to the salesperson achieves optimal customization of prices. Moreover, if the salesperson's compensation is based on gross margins rather than sales revenue, the objectives of the firm and the salesperson are identical; therefore, given the better knowledge of the customer, the salesperson should be given a good measure of pricing authority.

This line of reasoning has been formally developed by Weinberg (1975) and, more recently, Lal (1986). Specifically, Lal demonstrates that price delegation will be more profitable than centralization under conditions of asymmetric demand information. However, in his model, price dele- gation comes at a cost, in that the firm must pay salespeople a compensation premium (information rent) to motivate them to vary prices appropriately for different customers. Thus, the profitability of price delegation depends on whether the gains from price customization exceed the informational rents that need to be paid to the salespeople.

Dolan and Simon (1996) also present arguments against price delegation. They suggest that providing pricing authority to salespeople may make them too compliant in the negotiating situation. In other words, "there is the temptation to always play it safe to get the order" (Dolan and Simon 1996, p. 313). This line of reasoning has been formally examined by Berger (1972) and Weinberg (1975). Their research suggests that price delegation will be less profitable if the salesperson is risk averse. Another argument against price delegation is that it enables buyers to negotiate better prices. As an old purchasing axiom states, "Find out if the salesperson can reduce the price. If he can, insist that he do so" (Stephenson, Cron, and Frazier 1979, p. 27).

These explanations certainly enhance the understanding of the optimality of the price-delegation decision. Many of the practitioner comments can be evaluated in the context of formal models. For example, salespeople's ability to use their superior information is captured in Lal's (1986) model. Similarly, the observation that risk aversion may cause salespeople to discount suboptimally is suggested by Berger (1972) and Weinberg (1975). However, the issue of a suboptimal trade-off between effort and price has not been explicitly examined in the literature before. Therefore, I next develop a formal model that explicitly incorporates this trade-off.

\section{Research Setting}

The basic framework used in this study is in the tradition of decision-theoretic research on sales force compensation (Srinivasan 1981). In developing the features of my research setting, I am guided by two considerations. First, I rely on the simplest model that enables me to study the impact of the two forces I consider. Second, I use control mechanisms commonly employed in the practice of sales force management.

\section{Nature of Price Delegation}

As is revealed in previous research, price delegation is not a binary decision variable; firms typically offer varying levels of price latitude. These levels include no pricing authority, limited pricing authority, and full pricing authority. Because no pricing authority is a rigid condition, it is unlikely to be the optimal strategy in any market with a reasonable amount of diversity in customer willingness to pay. Therefore, in my research, I exclude this strategy and focus on the other two cases. Under limited pricing authority, price latitude is confined to a prespecified percentage of the list price or bounded by a price floor. In this scenario, both the price floor and the commission rate influence the salesperson's actions. Under full pricing authority, the salesperson has complete freedom to set any price above cost (assumed, without loss of generality, to be zero in the ensuing analysis), the only control being the commission rate. These two pricing policies are likely to encapsulate the practice of most firms in any given industry. In Stephenson, Cron, and Fra- 
FIGURE 1

Distribution of Reservation Values in the Market

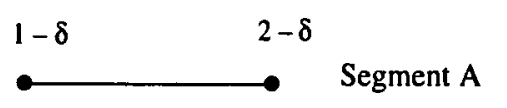

Segment B

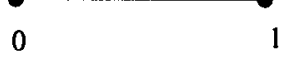

zier's (1979) sample, for example, these two policies describe the practices of $72 \%$ of the firms in the hospital supplies industry.

\section{Structure of the Market}

The market consists of two segments, A and B (see Figure 1). Customers in these segments buy either one unit of the firm's offering or nothing. Furthermore, customers in Segment $\mathrm{A}$ have reservation values for the product that are independently distributed and come from the uniform distribution $[1-\delta, 2-\delta], \delta>0$. (I discuss the significance of the parameter, $\delta$, subsequently.) Although these customers have positive economic value for the product, they have no previous awareness of its existence. Thus, they will purchase the firm's offering only if a salesperson contacts them and familiarizes them with the features of the product.

Segment B consists of customers who value the product to a lesser extent. Customers in this segment have reservation values that are independently distributed and come from the uniform distribution [0, 1]. Again, although these people have positive economic value for the firm's offering, they will make a purchase only if a salesperson contacts them and familiarizes them with the features of the product.

Finally, I assume that the firm views Segment A as its target segment. In essence, the role of the salesperson is to identify customers who value the product highly and promote it to them.' However, as can be expected, there is some overlap between the two segments. In particular, there are some customers in both segments whose valuations lie in the interval $[1-\delta, 1]$. The parameter $\delta$ is thus a measure of overlap between the two segments. It is reasonable to expect that its value will be greater than 0 but significantly less than 1. Of course, the firm is concerned primarily about the price obtained for the product; it is less concerned whether a particular customer belongs to Segment A or B. Nevertheless, given that customers in Segment A tend to have higher reservation values, the firm necessarily will encourage the salesperson to identify and pursue customers belonging to Segment A.

\section{Conceptualization of the Selling Function}

I conceptualize the selling function as consisting of two tasks, namely, prospecting and face-to-face communication.

\footnotetext{
IIndeed, sales organizations today are becoming increasingly concerned about targeting profitable customers. Specifically, in many industries, sales managers are encouraging salespeople to profile and target high-margin customers (Rasmusson 1999).
}

Prospecting consists of identifying customers who belong to the firm's target segment. Face-to-face communication consists of familiarizing the customer with product features. Although both activities are necessary components of the sales process, I view prospecting as the central task. Faceto-face communication, though important, simply follows as a matter of course after the potential customer has been identified. Such an abstraction of the selling process is consistent with the views expressed in textbooks on professional selling. Weitz, Castlebury, and Tanner (1998, p. 186), for example, write, "Many experts note that prospecting is the most important activity that a salesperson does." Furthermore, other aspects of the sales process, such as handling price objections, may never arise if the right customer is contacted.

Accordingly, although the selling function is characterized by two tasks, only the effort associated with prospecting plays an active role. The effort associated with face-to-face communication is included only for logical completeness. A little thought will show that this is not too stringent an assumption. After effort has been expended in gaining an audience with the prospect, it is in the salesperson's best interest to do the best job of face-to-face communication.

Next, I specify that the effort expended by the salesperson on prospecting is unobservable to the firm (or to the sales manager acting on behalf of the firm). However, through a quick perusal of the salesperson's call report, the firm can monitor the number of prospects contacted. Accordingly, the firm sets a target that the salesperson will call on $\mathrm{N}$ prospects during a given period. ${ }^{2}$ As mentioned previously, after the salesperson has called on a prospect, he or she simply familiarizes the customer with the features of the product in face-to-face communication. Clearly, in many real-world situations, face-to-face communication may also involve negotiating and boosting willingness to pay. These dynamics, though important, are outside the scope of the model.

\section{Prospecting Technology}

Given the aforementioned conceptualization of the selling function, the primary role of the salesperson is to identify target customers. The prospecting technology employed by the salesperson has the following features. Specifically, I assume that there is a large vector of variables, $Z$, that can help the salesperson identify customers who belong to Segment A. As outlined by Shapiro and Bonoma (1984), these variables may include demographic as well as situational factors. Moreover, as in discriminant analysis, the ability of these variables to correctly identify Segment A customers occurs with some error. However, the more variables, $z$, in $\mathrm{Z}$ that are used to screen a customer, the greater is the probability, $\phi$, that the customer belongs to Segment $A$. The parameter $\phi$ therefore may be interpreted as a measure of the quality of the prospecting strategy.

${ }^{2}$ This is a fairly typical way to monitor salesperson effort. Churchill, Ford, and Walker (1997, pp. 224-25), for example, document that sales organizations frequently use activity quotas that specify the number of calls that the salesperson should make on new accounts. 
I now posit a simple linear relationship between the number of screening variables used, $z$, and the quality of the prospecting strategy, $\phi$. In other words, the parameters $z$ and $\phi$ are interchangeable, except for a scaling parameter. The important notion of diminishing returns is introduced on the costs side, as described subsequently. This type of modeling has precedent in the sales force compensation literature, in which the notion of diminishing returns is captured by a linear response function and a quadratic cost function (see, e.g., the model formulations in Lal and Srinivasan [1993] and Joseph and Thevaranjan [1998]).

\section{Cost of Prospecting}

I next specify that the salesperson incurs a fixed cost, $\tau$, in interacting with a potential prospect. This cost may be thought of as the effort associated with initiating a precall interaction (letter, telephone call, and the like). Upon completing this interaction, the salesperson receives information that enables the customer to be described fully in terms of the vector $Z$.

In this scenario, the salesperson's decision variable is to choose the number of screening variables, $z$. As mentioned previously, this decision directly affects the quality of the prospecting strategy, $\phi$. Moreover, the greater the number of screening variables used, the larger is the number of customers the salesperson must contact and profile before finding one that is acceptable. I now specify a convex relationship between the number of customers to be contacted and the number of screening variables used. In other words, customers surviving screening become increasingly scarce as more and more screening variables are used. Mathematically, this convex relationship may be expressed by the quadratic expression $\gamma \mathrm{z}^{2}$, or equivalently, $\gamma \phi^{2}$. The parameter $\gamma$ represents a scaling parameter and is likely to be inversely related to the proportion of Segment A customers in the market. The cost of identifying a single prospect, $C(1)$, using a prospecting strategy with quality $\phi$ may now be written as

$$
C(1)=\tau \gamma \phi^{2} \text {. }
$$

Next, making the reasonable assumption that the size of the market is large relative to $\mathrm{N}$, the same cost structure holds for identifying each additional customer. Thus, the cost of identifying $\mathrm{N}$ prospects using a prospecting strategy of quality $\phi$ is given as

$$
C(N)=N \tau \gamma \phi^{2} \text {. }
$$

Replacing $\gamma \tau$ by a new parameter, $\lambda / 2$, Equation $\mathrm{Ib}$ can be rewritten as

$$
\mathrm{C}(\mathrm{N})=\mathrm{N} \frac{\lambda}{2} \phi^{2}
$$

The $1 / 2$ is introduced simply to reduce clutter in future equations. Accordingly, $\lambda / 2$ may be interpreted straightforwardly as the cost of effort associated with identifying a single prospect using a high-quality prospecting strategy $(\phi=1)$. It is convenient to call $\lambda$ the effort cost of following a high-quality prospecting strategy. It has the intuitively appealing property of being influenced by both market conditions (note that the fraction of customers who belong to Segment A affects $\gamma$ ) and a sales process variable (cost of precall interaction, $\tau$ ).
Given this prospecting technology, the quality of the prospecting strategy chosen by the salesperson directly affects the fraction of customers who belong to Segment $A$. Specifically, a given level of prospecting quality, $\phi$, gives rise to a situation in which $\mathrm{N} \phi$ of the $\mathrm{N}$ customers called on belong to Segment $A$. The remaining $N(1-\phi)$ customers belong to Segment $\mathrm{B}$.

\section{Information Structure}

In my research, I preserve the key notion that the salesperson possesses superior information about customers' willingness to pay. I further assume that upon visiting the prospect, the salesperson is able to identify precisely the reservation value of the customer and thus sets price equal to that reservation value. ${ }^{3}$ If the firm has a policy whereby the price must be above a certain floor (limited pricing authority case) and this floor exceeds the reservation value of the customer, the sale is not closed.

It is important to recognize that even though the firm is able to observe the price paid by each customer, it cannot infer the quality of the prospecting strategy and therefore the amount of effort devoted to prospecting. This is because the overlap in reservation prices between the two segments does not allow inferences to be made about the effort invested in prospecting. For example, if the salesperson obtains a price in the interval $[1-\delta, \delta]$, the firm cannot tell whether the salesperson worked hard to identify a Segment A customer or was simply lucky in obtaining a Segment B customer with a relatively high reservation value. In general, a given mix of $\mathrm{N}$ customers with realized prices coming from the three intervals- $[0,1-\delta],[1-\delta, 1]$, and $[1,2-\delta]$ - can be generated by several values of $\phi$. Because of this, observed prices are at best an imperfect signal for the level of effort devoted to prospecting. 4

\section{Compensation Plan}

Consistent with the research context, it is assumed that the salesperson is compensated on a linear commission rate, B, based on realized gross margins, $x$. Compensation, $S$, is thus written as

$$
\mathbf{S}=\mathbf{B} \mathbf{x} .
$$

\section{Salesperson's Utility Function}

As specified by Srinivasan (1981) and Basu and colleagues (1985), it is assumed that the salesperson is a utility-maximizer. The overall level of utility enjoyed by the salesperson consists of compensation less the cost of effort, which may now be written as

$$
\mathrm{U}=\mathrm{S}-\mathrm{N} \frac{\lambda}{2} \phi^{2}=\mathrm{Bx}-\mathrm{N} \frac{\lambda}{2} \phi^{2}
$$

\footnotetext{
${ }^{3}$ Again, considerations of negotiation, bargaining, and so forth are excluded because these forces are outside the scope of the model.

4 In theory, it is possible to contract on the distribution of realized prices and improve contracting efficiency. However, I do not consider such schemes because they are never observed in practice. In the industry analyzed by Stephenson, Cron, and Frazier (1979), for example, commissions are based simply on gross margins.
} 
The utility function described in Equation 3 assumes that the salesperson is risk neutral. In essence, issues of risk and risk sharing are not included in the analysis because Berger (1972) and Weinberg (1975) have already investigated the impact of salesperson risk aversion on price delegation.

\section{Analysis}

The analysis of the model is divided into three main parts. First, the profits of the firm are derived under full pricing authority. Second, the profits of the firm are derived under limited pricing authority. Third, firm profits under the two cases are compared and conditions are described in which each pricing strategy is optimal.

\section{Profits Under Full Pricing Authority}

In this scenario, the firm gives the salesperson full pricing authority, and control is effected solely through the compensation plan. The timing of efforts is sequential and is described as follows: The salesperson first prospects for customers with a quality level $\phi$. This yields $\mathrm{N} \phi$ customers who belong to Segment $A$ and $N(1-\phi)$ customers who belong to Segment $\mathrm{B}$. These $\mathrm{N}$ customers are then contacted and engaged in face-to-face communication.

Given a commission rate, B, the salesperson maximizes the following utility function:

$$
\underset{\phi}{\operatorname{Max}} \mathrm{BN} \phi \frac{3-2 \delta}{2}+\mathrm{BN}(1-\phi) \frac{1}{2}-\mathrm{N} \frac{\lambda}{2} \phi^{2} .
$$

In Equation 4, the first term represents commission income obtained from sales to the $N \phi$ customers in Segment A. Because the salesperson has full pricing authority, each of these transactions can be closed successfully. Moreover, the expected price obtained from these customers is simply the mean of the distribution of their reservation values, namely, $(3-2 \delta) / 2$. The second term represents commission income from the $\mathrm{N}(1-\phi)$ customers in Segment B. As discussed previously, the salesperson can consummate the sale with each of these customers. Here, the expected price obtained is $1 / 2$. Finally, the last term represents the disutility for effort. First-order conditions yield

$$
\phi=\frac{B(1-\delta)}{\lambda} .
$$

Next, knowing the salesperson's response to a given commission rate, $\mathrm{B}$, the firm chooses a commission rate that maximizes its profits. The firm's profit is the level of gross margins generated by the salesperson less commisions. Using Equation 5 and assuming zero marginal costs, the firm's problem may be formally written as

$$
\begin{aligned}
& \operatorname{Max}_{B}(1-B) N \frac{B(1-\delta)}{\lambda} \frac{3-2 \delta}{2} \\
& +(1-B) N\left[1-\frac{B(1-\delta)}{\lambda}\right] \frac{1}{2} .
\end{aligned}
$$

First-order conditions yield

$$
\mathrm{B}=\frac{1}{2}-\frac{1}{4} \frac{\lambda}{(1-\delta)^{2}} .
$$

Equation 8 reveals that the optimal commission rate decreases in the parameter that reflects the cost of effort, $\lambda$, as well as the overlap parameter, $\delta$. As $\lambda$ increases, it becomes more costly to induce effort through incentives; consequently, the firm finds it less attractive to use incentives. Similarly, as $\delta$ increases, the two segments become less distinct and prospecting becomes less valuable; consequently, the firm again relies on incentives to a lesser extent.

Finally, using Equations 7 and 8, the firm's expected profits, $E[\pi]$, may now be written as

$$
E[\pi]=\frac{1}{4} \frac{N(1-\delta)^{2}}{\lambda}+\frac{N \lambda}{16(1-\delta)^{2}}+\frac{N}{4} .
$$

Overall, the analysis here reveals that providing the salesperson with full pricing authority provides an important benefit, namely, the ability to match price to customer willingness to pay and thereby successfully complete all the $\mathrm{N}$ transactions.

\section{Profits Under Limited Pricing Authority}

As in the previous scenario, in which the salesperson has full pricing authority, the efforts are sequential in that prospecting is followed by face-to-face communication. In this situation, however, the firm yields only limited pricing authority in that the salesperson can discount only up to a predetermined floor. Theoretically, this floor can lie anywhere in the interval $[0,2-\delta]$. However, in the Appendix, it is shown that the firm will never choose to set a floor greater than $1-\delta$, the lowest reservation value possessed by a customer in Segment A. Consequently, the following equation assumes a price floor that, at most, takes the value $1-\delta$. Denoting this price floor by $\alpha, 5$ the salesperson maximizes the following utility function:

$$
\underset{\phi}{\operatorname{Max}} B N \phi \frac{3-2 \delta}{2}+B N(1-\phi)(1-\alpha) \frac{1+\alpha}{2}-N \frac{\lambda}{2} \phi^{2}
$$

In Equation 10, the first term represents the salesperson's commission income obtained from sales to customers in Segment A. Note that because the price floor is $\leq 1-\delta$, the salesperson can conclude sales with all $\mathrm{N} \phi$ customers in this segment. The second term represents commission income obtained from customers in Segment B. Here, given the price floor $\alpha$, the salesperson can conclude sales with only $(1-\alpha)$ fraction of these $\mathrm{N}(1-\phi)$ customers; some customers will not buy the product because it exceeds their willingness to pay. Moroever, the expected price obtained from these customers is $(1+\alpha) / 2$. Finally, the third term represents the disutility for effort. First-order conditions yield

$$
\phi=\frac{\mathrm{B}\left(1-\delta+.5 \alpha^{2}\right)}{\lambda} \text {. }
$$

Equation 6 can be simplified to

$$
\operatorname{Max}_{B}(1-B) B N \frac{(1-\delta)^{2}}{\lambda}+(1-B) \frac{N}{2} \text {. }
$$

${ }^{5}$ Note that $\alpha=0$ corresponds to the full pricing authority case. 
Comparing Equation 11 with Equation 5 reveals a key benefit of limiting pricing authority. Specifically, limiting pricing authority forces the salesperson to increase the quality of prospecting $\left(1-\delta+.5 \alpha^{2}>1-\delta\right.$ for all $\left.\alpha>0\right)$. In effect, the lack of pricing flexibility causes the salesperson to realize that poor prospecting cannot be offset by price discounting; consequently, the salesperson expends greater effort on prospecting.

As previously, knowing the salesperson's response to a given price floor and commission rate, the firm chooses the optimal values of these variables. From Equation 11, the firm's problem may be written formally as

$$
\begin{gathered}
\operatorname{Max}_{\alpha, \mathrm{B}}(1-\mathrm{B}) \mathrm{N} \frac{\mathrm{B}\left(1-\delta+.5 \alpha^{2}\right)}{\lambda} \frac{3-2 \delta}{2}+ \\
(1-\mathrm{B}) \mathrm{N}\left[1-\frac{\mathrm{B}\left(1-\delta+.5 \alpha^{2}\right)}{\lambda}\right](1-\alpha) \frac{1+\alpha}{2} .
\end{gathered}
$$

First-order conditions yield

$$
B=\frac{1}{2}-\frac{\lambda\left(1-\alpha^{2}\right)}{\left[2-2 \delta+\alpha^{2}\right]^{2}}
$$

As in the case of full pricing authority, Equation 13 reveals that the optimal commission rate decreases in the parameter that reflects the cost of effort, $\lambda$, as well as the overlap parameter, $\delta$. In addition, Equation 13 reveals that the level of incentives increases as the price floor, $\alpha$, increases. In other words, at the optimum, restricting the salesperson's freedom with respect to pricing should be accompanied by an increase in the commission rate. This finding forms the basis for $\mathrm{P}_{2}$, which is discussed in greater detail in the Findings section.

From Equations 12 and 13, the firm's expected profits may now be written as

$$
\begin{gathered}
E[\pi]=\frac{N\left(2-2 \delta+\alpha^{2}\right)^{2}}{16 \lambda}+\frac{N \lambda\left(1-\alpha^{2}\right)^{2}}{4\left(2-2 \delta+\alpha^{2}\right)^{2}} \\
+\frac{N\left(1-\alpha^{2}\right)}{4} .
\end{gathered}
$$

Overall, the analysis here reveals that the benefit of limiting pricing authority is that it forces the salesperson to exert greater effort on prospecting. However, a limitation of this strategy is that some sales transactions are not completed because price exceeds the customer's reservation value. Thus, it is not obvious how limited pricing authority will compare with full pricing authority. Therefore, the profits across the two scenarios will be analyzed next for the sake of comparison.

\section{Optimality of Price Delegation}

As suggested in the previous subsection, I compare Equations 9 and 14 to describe the optimal level of price delegation. 6 Because the analytical expressions in these equations

6In comparing Equations 9 and 14, the parameters are varied in the following fashion: $\lambda$ in steps of $1, \delta$ in steps of .025 , and $\alpha$ in steps of .01 . At each $\lambda-\delta$ point, the profit in Equation 9 is compared with the profit in Equation 14 using a value of $\alpha \in[0,1-\delta]$ that maximizes Equation 14. If Equation 9 has a larger value than Equation 14, then full pricing authority is the optimal strategy; otherwise, limited pricing authority is the optimal strategy. are not very tractable, I use numerical techniques. Moreover, because both profit functions include the term $\mathrm{N}$, it is appropriate to restrict the evaluation of firm profits to the $\lambda-\delta$ parameter space. The parameter $\lambda$ has no natural limits; nevertheless, the interval $[0,1]$ is found to be sufficient to present findings of interest. The parameter $\delta$, in contrast, represents the overlap in the segmentation scheme. As such, it will be some positive number significantly less than 1. For the purposes of this research, the interval $[0, .10]$ is found to be sufficient to present findings of interest. The key results are displayed in Figure 2 and discussed in the next section.

\section{Findings}

I summarize the main findings in terms of two key propositions. $P_{1}$ demonstrates that the optimality of delegating pricing authority varies across the parameter space. $\mathrm{P}_{2}$ demonstrates how the commission rate varies with the price delegation decision.

$P_{1}$ : Full price delegation is not optimal in all parts of the parameter space. Specifically, for a given value of the overlap parameter, $\delta$, the optimality of full price delegation varies nonmonotonically with the effort cost of following a high-quality prospecting strategy, $\lambda$. In particular, when $\lambda$ is relatively low or relatively high, full price delegation is the optimal strategy. However, when $\lambda$ takes on intermediate values, limited price delegation is the optimal strategy.

Figure 2 reveals that the parameter space splits into four distinct regions. In Region I, the cost of following a highquality prospecting strategy is relatively low. Consequently, the optimal commission rate under full pricing authority is such that it induces the salesperson to follow a high-quality prospecting strategy (i.e., induces $\phi=1$ ). As such, there is no cost to granting full pricing authority to the salesperson

\section{FIGURE 2 \\ Optimality of Price Delegation}

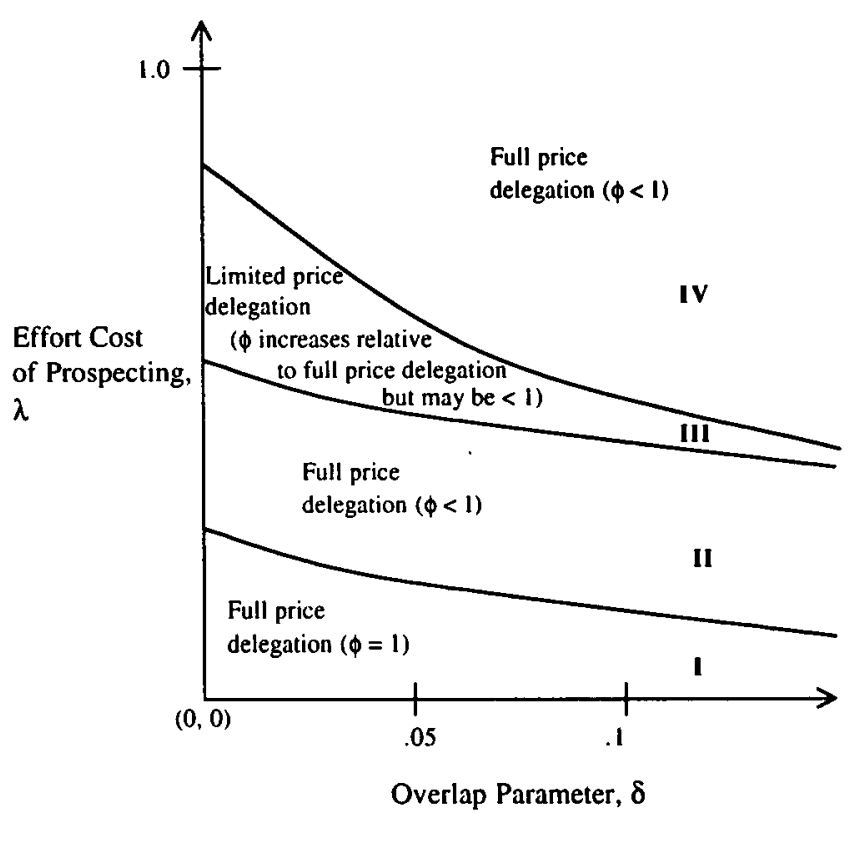


because the opportunity to make suboptimal trade-offs between effort and price does not arise in the first place.

In Region II, the optimal commission rate under full pricing authority is such that it induces less-than-full attention to prospecting $(\phi<1)$. Therefore, as is concluded in the discussion following Equation 11, limiting pricing authority will increase the effort devoted to prospecting. Nevertheless, in this region, limiting pricing authority is not profitable because the level of effort induced by the commission rate under full pricing authority is close to ideal (recall that $\lambda$ is still relatively low in this region). Thus, although limiting pricing authority can increase $\phi$, the incremental gain is not worth the loss in sales arising from the lack of pricing flexibility.

Next, in Region III, the optimal solution is indeed to limit pricing authority. Here, $\lambda$ takes on an intermediate value; consequently, the effort induced by incentives under full pricing authority is relatively low. Thus, in this region, limiting pricing authority has the potential to increase the effort devoted to prospecting substantially. ${ }^{7}$ Unlike in Region II, this improvement in effort is accompanied by an improvement in firm profits as well. In effect, limiting pricing authority forces the salesperson to target high-valuation customers, and this benefit exceeds the loss in sales arising from the lack of pricing flexibility.

Finally, in Region IV, the optimal strategy is again to resort to full pricing authority. In this region, the effort cost of following a high-quality prospecting strategy is relatively high; consequently, forcing more attention on prospecting by limiting pricing authority is simply not cost effective.

$\mathrm{P}_{2}$ : In the region where limiting pricing authority is the optimal strategy, the commission rate offered to the salesperson under limited pricing authority is higher than the corresponding commission rate offered to the salesperson under full pricing authority.

$\mathrm{P}_{2}$ demonstrates that a firm making the transition from full pricing authority to limited pricing authority also needs to increase the commission rate offered to the salesperson. Intuitively, this is because limiting pricing authority enhances the effectiveness of commissions in inducing effort; consequently, the firm prefers to use incentives to a greater extent. $P_{2}$ is interesting because it is counterintuitive. Limiting the salesperson's freedom with respect to pricing would be expected to be accompanied by a relaxation in the emphasis placed on the other element of the control system, namely, the commission rate. In contrast, according to the model, limiting pricing authority increases the emphasis that needs to be placed on commissions.

\footnotetext{
7Three points may be of interest to the technically oriented reader. First, when the overlap parameter, $\delta$, exceeds .17 , Region III vanishes altogether and full pricing authority is always the optimal solution. Intuitively, as $\delta$ increases, the two segments become less distinct and the need for prospecting decreases. This, in turn, eliminates the need for inducing greater effort through a strategy of limited pricing authority. Second, the optimal price floor $(\alpha)$ in most of Region III is either equal to or close to $1-\delta$. Third, the relatively small area captured by Region III does not imply that this solution will occur infrequently in practice.
}

\section{Discussion and Managerial Implications}

In this research, I develop and analyze a model that formally examines the optimality of delegating pricing authority to the sales force. I find that there are environments in which full price delegation is the optimal course of action and others in which limited price delegation is the best strategy. As mentioned previously, this is an important theoretical finding because it has the potential to reconcile the conflicting empirical evidence reported in the literature with respect to the decision to delegate pricing authority.

An appealing feature of my model is that it explicitly incorporates the general complaint that price delegation causes salespeople to reduce their selling efforts. Specifically, the analysis reveals that giving salespeople full pricing authority may lead to situations in which salespeople use discounts to garner sales rather than expend effort to pursue customers who value the product highly. Thus, in some situations, it makes sense for the firm to limit pricing authority even though the salesperson has superior information about customer willingness to pay. Moreover, the analysis also reveals that limiting the amount of pricing authority and increasing the commission rate combine synergistically to ensure that the salesperson indeed vigorously pursues these customers. This combination of control elements is counterintuitive. Intuition would suggest that the commission rate should be higher when the salesperson has greater latitude with respect to pricing.

I summarize the context, calculus, and main implications of the model in Table 1 with a view to assisting sales managers charged with the price-delegation decision. Hopefully, the context described by the model is not overly restrictive and many sales organizations will find the essential features relevant. However, practitioners need to be alerted that several other factors, such as those highlighted by Stephenson, Cron, and Frazier (1979), will also play a role in determining the optimality of the price-delegation decision. Nevertheless, the model succinctly describes the net impact of two forces that pertain to the price-delegation decision, namely, superior salesperson information about customer willingness to pay and suboptimal effort-price tradeoff. As such, it should prove useful to managers charged with the price-delegation decision.

In the future, it is likely that the importance of price customization will increase as sales organizations use information-age technology to reach more diverse markets. Thus, it is likely that the questions of whether pricing authority should be granted to salespeople and, if so, how much authority is granted will continue to be of interest to academicians and practitioners alike. The present study should stimulate additional research, especially on the empirical side, that will deepen the understanding of price delegation in sales organizations.

\section{Appendix}

Here, I show that the firm will never find it profitable to set a price floor above $1-\delta$. To understand this, consider the following: Suppose the firm sets a price floor that is greater 
TABLE 1

Model Context, Calculus, and Implications

\section{Model Context}

The model is set in selling environments in which

-Customers vary widely in their valuations of the firm's offering;

-Prospecting, that is, identifying customers with high valuations, is a significant component of the selling task; and

- Commissions based on gross margins serve as an important control element.

\section{Model Calculus}

Limiting pricing authority can serve as an additional control element; it provides an important benefit but comes at a cost:

-Benefit: forces the salesperson to devote greater attention to prospecting because the ability to close sales by discounting has been curtailed.

- Cost: prevents the salesperson from matching price to customer willingness to pay; consequently, fewer transactions are completed.

\section{Model Implications}

\section{Effort Cost \\ of Following a \\ High-Quality \\ Prospecting \\ Strategy}

Relatively low

Intermediate

Limited pricing authority and increased reliance on commissions

Relatively high

Full pricing authority
Control Structure

Intuition
Because the effort cost of following a high-quality prospecting strategy is relatively low, commissions alone can ensure sufficient attention to prospecting. In addition, full pricing authority provides salespeople the ability to conclude a greater fraction of transactions.

Limiting pricing authority forces greater attention to prospecting because the ability to discount price has been curtailed. In addition, increased reliance on commissions reinforces the importance of targeting high-valuation customers.

Because the effort cost of following a high-quality prospecting strategy is relatively high, it is not cost effective to induce more effort on prospecting by limiting pricing authority. The firm gains more by giving the salespeople pricing freedom so that they conclude a greater fraction of transactions. than $1-\delta$ but less than 1. Denoting this price floor by $1-$ $\delta+\Delta$, the salesperson's problem is given by

$$
\begin{gathered}
\underset{\phi}{\operatorname{Max}} \mathrm{BN} \phi \frac{3-2 \delta+\Delta}{2}(1-\Delta) \\
+\mathrm{BN}(1-\phi) \frac{2-\delta+\Delta}{2}(\delta-\Delta)-\mathrm{N} \frac{\lambda}{2} \phi^{2} .
\end{gathered}
$$

In Equation $\mathrm{Al}$, the first term represents sales from customers in Segment $A$. With a price floor of $1-\delta+\Delta$, the expected price is $(3-2 \delta+\Delta) / 2$, and the salesperson can conclude sales with $(1-\Delta)$ fraction of customers in Segment $A$. The second term represents sales from customers in Segment B. For these customers, the expected price is $(2-$ $\delta+\Delta) / 2$, and the salesperson can conclude sales with $(\delta-\Delta)$ fraction of these customers. First-order conditions yield

$$
\phi=\frac{\mathrm{B}\left(1.5-2 \delta+.5 \delta^{2}\right)}{\lambda} .
$$

Equation A2 reveals that the level of effort induced is independent of $\Delta$. In other words, the effort that is induced is constant for all $\alpha \in[1-\delta, 1]$. However, setting a price floor in this interval is costly because it will exclude some customers. Thus, the firm will never find it profitable to set such a price floor.

Finally, a little' thought will show that the firm will not want to set a price floor greater than 1 either. In effect, setting a floor above this level simply excludes customers that the salesperson should be calling on in the first place, namely, the firm's target segment.

\section{REFERENCES}

Basu, Amiya K., Rajiv Lal, V. Srinivasan, and Richard Staelin (1985), "Salesforce Compensation Plans: An Agency Theoretic Perspective," Marketing Science, 4 (4), 267-91.

Berger, P.D. (1972), "On Setting Optimal Sales Commissions," Operational Research Quarterly, 23 (June), 213-15.
Churchill, Gilbert A., Neil M. Ford, and Orville C. Walker (1997), Salesforce Management. Chicago: Richard D. Irwin.

Dolan, Robert and Hermann Simon (1996). Power Pricing. New York: The Free Press.

Joseph, Kissan and Alex Thevaranjan (1998), "Monitoring and 
Incentives in Sales Organizations: An Agency-Theoretic Perspective," Marketing Science, 17 (2), 107-23.

Lal, Rajiv (1986), "Delegating Pricing Responsibility to the Salesforce," Marketing Science, 5 (2), 159-68.

and V. Srinivasan (1993), "Compensation Plans for Single and Multi-Product Salesforces: An Application of the Holmstrom-Milgrom Model," Management Science, 39 (July), 777-93.

Moorthy, Sridhar K. (1993), "Theoretical Modeling in Marketing," Journal of Marketing, 57 (April), 92-106.

Rasmusson, Erika (1999), "Wanted: Profitable Customers," Sales and Marketing Management, 151 (May), 29-34.

Shapiro, Benson P. and Thomas V. Bonoma (1984), "How to Segment Industrial Customers," Harvard Business Review, 62 (May/June), 103-10.
Srinivasan, V. (1981), "An Investigation of the Equal Commission Rate Policy for a Multi-Product Salesforce," Management Science, 27 (July), 731-56.

Stephenson, Ronald P., William L. Cron, and Gary L. Frazier (1979), "Delegating Pricing Authority to the Salesforce: The Effects on Sales and Profit Performance," Journal of Marketing, 43 (Spring), 21-28.

Weinberg, Charles B. (1975), "An Optimal Commission Plan for Salesmen's Control over Price," Management Science, 21 (April), 937-43.

Weitz, Barton A., Stephen B. Castleberry, and John F. Tanner (1998), Selling: Building Relationships. Boston: Irwin/ McGraw-Hill.

\title{
Hail Community College \\ Hail, Saudi Arabia
}

Under the auspices of King Fahd University of Petroleum \& Minerals, Dhahran, Saudi Arabia

\section{Dept. of Business Administration}

$$
\text { (Ref. BA 001) }
$$

Applications are invited for Faculty positions at Hail Community College starting in September 2001 or January 2002. Applicants should be well qualified, committed and adaptable. Successful applicants will be offered positions at Associate/Assistant Professor or Lecturer level and will be expected to lecture at Undergraduate/Associate Degree level and/or on the Preparatory Year Program level and to undertake other duties as required by the College. The medium of instruction at the College is English and the College currently has vacancies in the following areas:

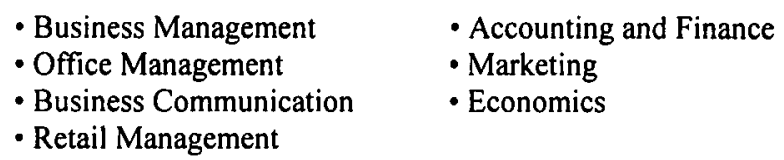

\section{- Business Statistics \\ - Investment \\ - M.L.S.}

All Contracts: Two-year renewable contract; competitive salaries depending on qualifications and experience; monthly local transportation allowance and an end-of-service gratuity.

Benefits: Married and single status appointments (please note; there are no International School facilities for school age children); rent-free, air conditioned, furnished accommodations including basic utilities; two months paid summer leave each year; annual flights.

\author{
To apply mail or fax cover letter and detailed CV to: \\ DEAN, HAIL COMMUNITY COLLEGE \\ P.O. BOX 2440 \\ HAIL, SAUDI ARABIA \\ FAX: 966-6-531-0500
}

Contact for further information: E-Mail: manaaafa@kfupm.edu.sa

Please quote the position and relevant reference number in all correspondence 